\title{
DEFLATION AND OUTPUT ACROSS SECTORS: RESULTS FOR THE CZECH REPUBLIC
}

\author{
Pavel Ryska, Petr Sklenár
}

\section{Introduction}

The study of deflation seems to be gaining ever more importance. Central banks in most advanced economies, including the European Central Bank and the Czech National Bank, have observed $\mathrm{CPI}$ inflation running below their targets or even in outright deflationary territory. These central banks argue that deflation should be avoided at all costs and employ extraordinary policies such as quantitative easing, foreign exchange interventions or negative nominal interest rates to fight against it. As these policies have not always led to higher economic growth and higher inflation, there have been calls for even more extraordinary measures. Among those is a proposal to abolish cash money in order to allow banks to carry over the negative interest rates more efficiently on their depositors and stoke inflation (see e.g. Buiter, (2009) or Rogoff (2014)). Therefore, a lot is at stake in knowing whether deflation (especially mild deflation) should be avoided by all means.

There are substantial problems with studies that have tried to assess the relationship between economic growth and the price level. First, all of them have used aggregate data for countries such as GDP and CPI. While aggregate variables provide information about the economy as a whole, they cannot reveal the potential variation in output and prices that takes place 'inside' the economy. As a result, we know very little about whether firms and sectors within the economy face deflation and where it comes from. We can also hardly assess whether deflationrecession theories hold. Second, episodes of deflation in the aggregate CPI or in the GDP deflator have been scarce in the past decades. As a result, studies on deflation have had to rely on historical data, often before World War I. Whatever these studies show, their conclusions can be criticized as irrelevant, because they are based on outdated observations.
In this paper, we take a different approach. Instead of using aggregate data on GDP and inflation, we focus on sector data on production and prices. Specifically, we use data from the Czech Statistical Office on production, gross value added and prices in sectors of the Czech economy from 1993 to 2015 . This dataset has three advantages: (1) it is rich in information on firms' output and inputs, (2) it provides recent observations, and (3) it contains numerous episodes of sector deflation, which would on the macroeconomic level be concealed under the aggregate CPI or deflator numbers. We think this approach is novel: we do not know of another study that would analyze deflation and growth using sector data.

We find that, contrary to common wisdom, deflationary pressures in the Czech economy have been coming from sectors with increasing output and increasing gross value added, not from the deteriorating ones. This shows that deflation was most often growth-driven, representing rising productivity.

This text proceeds as follows. In Section 1, we present the current state of research on deflation and show its main drawbacks. In Section 2, we present our sector data from national accounts. We first show some descriptive statistics in Section 3. We then perform regression analysis in Section 4, where we use the fixed effects model and General Method of Moments estimation to regress the growth in production and gross value added on the growth of prices plus control variables. The last section concludes the paper.

\section{Current Research}

\subsection{Empirical Studies}

There are three main lines of reasoning why deflation is thought by many to be harmful for economic growth. First, the expectation of falling prices may delay spending by consumers 
and businesses. Firms see their revenues fall and if they cannot adjust wages and other costs accordingly, their margins shrink and they have to lay off workers. Second, for a given nominal interest rate, deflation raises the real interest rate, which in turn might deter investment. Third, if there is significant indebtedness in the economy, deflation may cause bankruptcies as it increases the real value of debt.

Several studies have attempted to assess empirically whether the alleged link between deflation and recession holds. Bordo and Redish (2003) restrict their attention to the United States and Canada in the period 18701913 , which was rich in episodes of deflation. They find that prices did not affect output. Bordo, Lane and Redish (2004) add Germany to the sample and reach a similar conclusion. Other recent studies use long datasets that span more than a century and contain many countries. Atkeson and Kehoe (2004) conclude from their regression of output growth on growth of prices that in the whole sample, the correlation is close to zero. An exception is the subsample of the Great Depression in the 1930s, where the link was positive. Borio and Filardo (2004) as well as Borio et al. (2015) generally confirm this result. By contrast, Guerrero and Parker (2006) lean to the conclusion that deflation is bad for growth, finding an economically small but statistically significant link. According to them, lagged deflation negatively affects output. Benhabib and Spiegel (2009) find a non-linear relationship between deflation and recession.

In recent years, some researchers have focused on the link between expected inflation (or deflation) and consumption. Interestingly, they have produced starkly different results. Bachmann, Berg and Sims (2015), using recent data on the US economy, refuse the hypothesis that the expectation of deflation leads to lower present consumption. By contrast, Ichiue and Nishiguchi (2014) support this hypothesis using survey data on modern Japan.

Overall, the existing empirical work on deflation is rather limited - which is surprising given its importance for monetary policy - and inconclusive. As we explain below, there is a major problem of applicability of the majority of these studies to modern-day monetary policy.

\section{2 'Good' or 'Bad' Deflation?}

Two lines of thought can be traced in current mainstream macroeconomics. The first group considers deflation decisively harmful and studies ways to avoid it. Here we can include influential macroeconomists Krugman (1998), Bernanke (2002) or Svensson (2003).

The second group takes a more detailed look at deflation. Bordo and Redish (2003) coined the terms 'good' and 'bad' deflation. Deflation is of the good type if is associated with rising output. In particular, good deflation occurs when firms invest to decrease unit costs and increase output. As a result, if the economy operates with a constant money supply, consumers buy an increased output with the same amount of money, so the price level decreases. This is a synonym for an outward shift in the aggregate supply curve. This situation is thought to have been typical for the pre-World War I period.

By contrast, bad deflation is associated with falling output. In this case, deflation results from decreasing nominal demand, which cannot be immediately passed on to lower prices of inputs. Firms see their profitability decrease and cut production. This was most probably one of the characteristics of the Great Depression of the 1930s.

Other works adhering to this distinction between good and bad deflation include Beckworth (2007), Bordo and Filardo (2005) and to a certain extent also Borio et al. (2015).

The terms good and bad deflation do not describe causality - they only describe correlations. For example, bad deflation does not necessarily mean that deflation causes falling output. Decreasing prices may only be a symptom of falling demand, not the root cause itself. However, the terms may be useful in practice because policymakers try to determine the type and decide whether they should or should not counteract it. If deflation results from decreasing nominal demand, central banks consider it undesirable and prefer to offset it by easing policy. On the contrary, if it results from cheaper production without direct link to demand, central banks may be more willing to let such deflation run its course. Therefore, if we find that most deflation going on in the economy is of the good type, it may have a direct policy implication.

For these purposes, the existing empirical research has a clear disadvantage. All the studies mentioned in Section 1.1 use only aggregate macroeconomic variables, most often the GDP and CPI inflation. This causes a trade-off: the aggregate annual data do not 
show almost any years with deflation in the last decades for most developed economies (For the Czech Republic, too, the aggregate price deflator shows only one year with deflation in the period 1993-2015.). When researches want to use aggregate data and learn more about deflation, they have to use pre-World War I data which are rich in observations of deflation. But then the results are based on old observations which may have little relevance for today because monetary regimes have changed, there are starkly different levels of debt, there is more financial intermediation, etc.

By contrast, using sector data, we have many episodes of modern-day deflation and we circumvent the trade-off. We are thus better equipped to make judgments about a potential link between prices and output and to assess particular deflation-recession theories. (Below we use the terms inflation and deflation also for the change of sector prices. Some may insist that inflation and deflation denote only aggregate price movements, but not sector price movements. However, all aggregate numbers have their sources in their components, and it is precisely these sources that we analyse below. Thus we use inflation and deflation in the broader sense.)

\section{Data}

We use data from the Czech Statistical Office (2017). It has complete data on 86 sectors of the Czech economy as defined in national accounts. The definition of each industry is based on NACE classification and values are published in the statistics of National Accounts. The data spans from 1993 to 2015.

As we use growth in variables rather than levels, one time period drops out, so we have 22 time periods. That gives a total of 1892 observations. The variables are output prices (implicit price deflator), output, gross value added (GVA), employment and intermediate inputs. Output, GVA, employment and intermediate inputs are available both in nominal and real terms, but in this article we use them in real terms (i.e., in constant prices) as we are interested in assessing the effect of prices on real output of firms.

An important feature of the NACE classification is that it does not cover only sectors producing for final consumption, but also sectors upper in the production chain - i.e., sectors producing capital goods and intermediate inputs. As a result, firms' output does not mean only consumer goods bought by consumers, but also capital goods bought by other firms.

\section{Fig. 1: Production and GVA growth against change of prices}
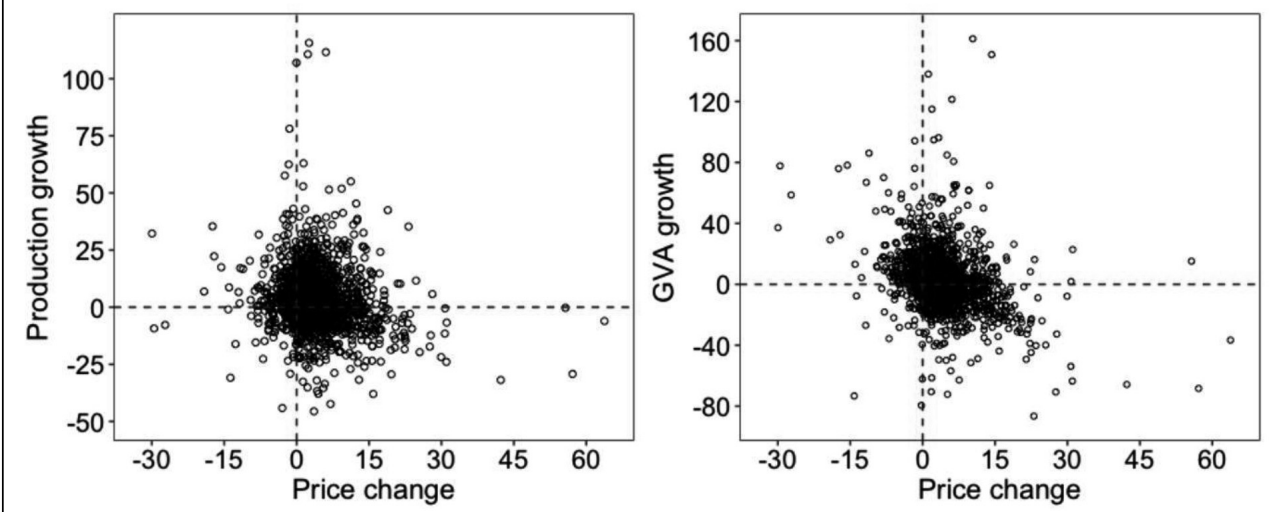


\section{Descriptive Statistics}

In our sample, positive price growth prevails and accounts for $80 \%$ of all observations (see Fig. 1). At the same time, approximately three fifths of observations have positive growth of production and gross value added. As a result, roughly half of observations lie in the top-right quadrant in Fig. 1. In this section we focus on basic statistical relationships between the sign of price change (inflation/deflation) and the sign and growth rate of production or GVA. In particular, we focus on whether declines in production are associated with deflation.

In Tab. 1, we report the comparison of growth in production and gross value added under increasing versus decreasing prices. We also visualize the comparisons with density graphs in Fig. 2. Out of observations with price deflation, $69.7 \%$ recorded positive growth in real production, while the corresponding percentage for observations with inflation is only $58.8 \%$. This is also reflected in the averages: the average growth rate of production during episodes of price deflation is $5.47 \%$, which is sizably higher than the average growth with inflation $(2.85 \%)$. Therefore, this preliminary observation contradicts the notion that deflation is linked to subpar output growth. To check this finding, we also ran a formal test of equality of means. As seen in Tab. 2, the t-test rejects the null hypothesis that the average production growth under inflation is equal to that under deflation, thereby confirming the finding. In contrast, the standard deviations of growth rates are similar, which is also supported by the testing of equality of variances.

\section{Tab. 1: Growth of production and GVA under inflation and deflation}

\begin{tabular}{l|c|c|c} 
& All data & Inflation & Deflation \\
\hline Observations & 1,892 & 1,509 & 383 \\
\hline Production & & & \\
\hline obs. with production increase & $61.00 \%$ & $58.80 \%$ & $69.70 \%$ \\
\hline obs. with production decrease & $39.00 \%$ & $41.20 \%$ & $30.30 \%$ \\
\hline Mean growth & 3.38 & 2.85 & 5.47 \\
\hline Standard deviation of growth & 12.89 & 12.71 & 13.39 \\
\hline Gross value added & & & \\
\hline obs. with GVA increase & $57.50 \%$ & $52.30 \%$ & $77.80 \%$ \\
\hline obs. with GVA decrease & $42.50 \%$ & $47.70 \%$ & $22.20 \%$ \\
\hline Mean growth & 3.40 & 0.68 & 14.10 \\
\hline Standard deviation of growth & 34.86 & 25.74 & 57.05 \\
\hline
\end{tabular}

Source: Czech Statistical Office (2017), own computations

We performed the same analysis also for real gross value added (see Tab. 1). Here the better performance under deflation is even more pronounced: $77.8 \%$ of deflationary observations report positive growth in gross value added, while for inflationary observations the percentage is only $52.3 \%$. The average growth of gross value added is $14.1 \%$ with deflation, while only $0.68 \%$ with inflation. The difference is also confirmed by the t-test. The only difference with gross value added as opposed to production is the higher standard deviation with deflation than with inflation.
The reason for these rather convincing findings may be the prevalence of 'good deflation' in our sample: the sectors that reported product price deflation could be precisely the ones that invested most in production and therefore enabled cheaper and greater production. Anyway, this preliminary look runs against the claim that deflation harms prospects for growth.

In the Appendix, we reverse our perspective and ask the question how much growth in prices there is under the opposite scenarios of rise and fall in production and GVA. 


\section{Ekonomie}

Tab. 2:

Tests of equality of means and variances

\begin{tabular}{l|c|c} 
& Test statistic & p-value \\
\hline Production & & \\
\hline t-test for equality of means & $3.44^{\star * *}$ & $<0.001$ \\
\hline F-test for equality of variances & 1.11 & 0.19 \\
\hline Gross value added & & \\
\hline t-test for equality of means & $4.49^{* \star *}$ & $<0.001$ \\
\hline F-test for equality of variances & $4.91^{* \star *}$ & $<0.001$
\end{tabular}

Source: Czech Statistical Office (2017), own computations

Note: We use the Welch t-test, i.e., a standard unpaired and two-sided t-test to determine whether the means of production growth under inflation and deflation are equal to each other. The null hypothesis is that the two means are equal. To test the equality of variances, we use an F-test, where the null hypothesis is that the ratio of the variances of the samples is equal to 1 .

Note: The sign ${ }^{* * *}$ denotes significance at $1 \%$ level.

\section{Fig. 2: Density of production and GVA growth under deflation and inflation}
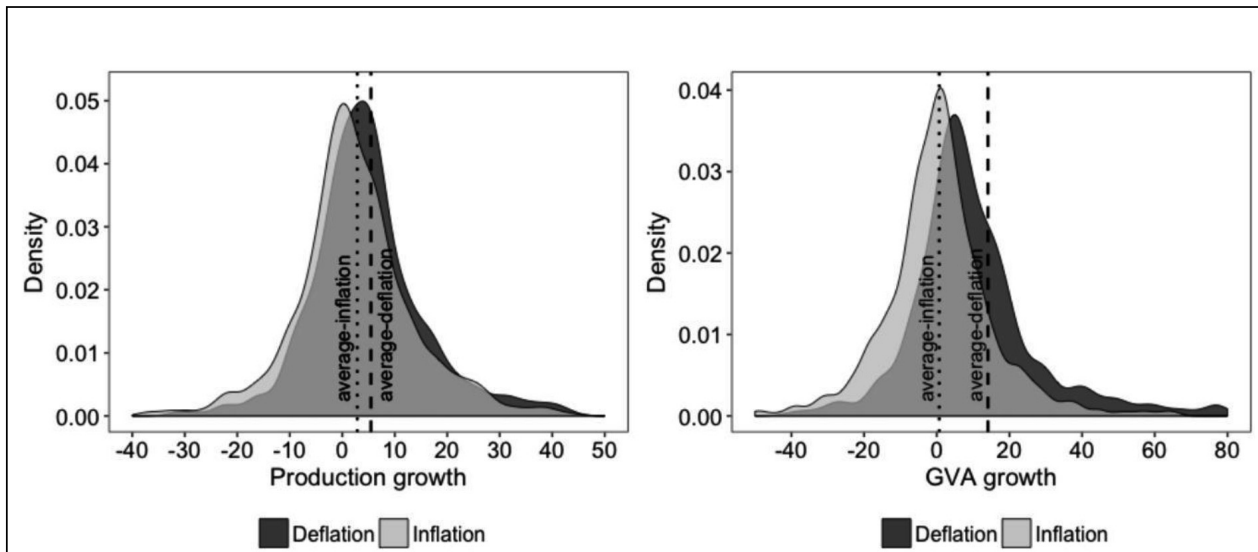

This complements our result here that slower price growth or outright deflation is accompanied by quicker output growth.

\section{Regression Analysis \\ 4.1 Time Averages}

As a first look on correlations, we performed a simple regression of time averages. We regressed average annual output growth in the 86 sectors of the Czech economy over 1993-
2015 on the corresponding average annual price growth, as seen in Tab. 3 .

In what follows below, we denote $x$ the annual percentage change in variable $X$. That is, $p$ is the growth in prices, $q$ in real output (production) and gva in real gross value added. We tested the results in Tab. 3 for the presence of heteroscedasticity and whenever it was detected we used the White's heteroscedasticity-corrected covariance matrix. 


\begin{tabular}{|c|c|c|c|c|}
\hline \multicolumn{5}{|c|}{$\begin{array}{l}\text { Time averages: Regression of average annual growth in output and GVA } \\
\text { on inflation }\end{array}$} \\
\hline & \multicolumn{2}{|c|}{ All data } & \multicolumn{2}{|c|}{ Without outlier } \\
\hline & Coefficient & p-value & Coefficient & p-value \\
\hline \multicolumn{5}{|l|}{ Regressing q on: } \\
\hline Intercept & $7.082^{* \star \star}$ & $<0.001$ & $-6.118^{\star \star \star}$ & $<0.001$ \\
\hline$p$ & $-1.142^{* * *}$ & $<0.001$ & $-0.919^{* * *}$ & $<0.001$ \\
\hline Observations & \multicolumn{2}{|c|}{86} & \multicolumn{2}{|c|}{85} \\
\hline Adj. $R^{2}$ & \multicolumn{2}{|c|}{0.237} & \multicolumn{2}{|c|}{0.167} \\
\hline \multicolumn{5}{|l|}{ Regressing gva on: } \\
\hline Intercept & $8.996^{* * *}$ & $<0.001$ & $8.824^{* * *}$ & $<0.001$ \\
\hline$p$ & $-1.998^{* * *}$ & $<0.001$ & $-1.819^{* * *}$ & $<0.001$ \\
\hline Observations & \multicolumn{2}{|c|}{86} & \multicolumn{2}{|c|}{85} \\
\hline Adj. $R^{2}$ & \multicolumn{2}{|c|}{0.380} & \multicolumn{2}{|c|}{0.323} \\
\hline
\end{tabular}

Source: Czech Statistical Office (2017), own computations

Note: The sign ${ }^{* * *}$ denotes significance at $1 \%$ level.

The regression coefficient on $p$ (percentage growth in prices) is -1.142 , significant at $1 \%$, suggesting that slower price growth has been associated with faster output growth. As depicted in Fig. 3, there is one distinct outlier on top left. This sector is the manufacturing of computer, electronic and optical products. Interestingly, it is both the sector with the fastest growth rate of production and the only sector with average annual deflation over 19932015. We also ran the regression without this outlier, but the negative coefficient and high statistical significance remain (see Tab. 3). We tried leaving out up to 10 most extreme observations, but the negative and statistically significant coefficient for $p$ remained.

We can observe the general pattern of the sectors in the Czech economy from Fig. 3: while

\section{Fig. 3: Regressing time averages: (a) Output growth on inflation, (b) GVA growth on inflation (all data)}
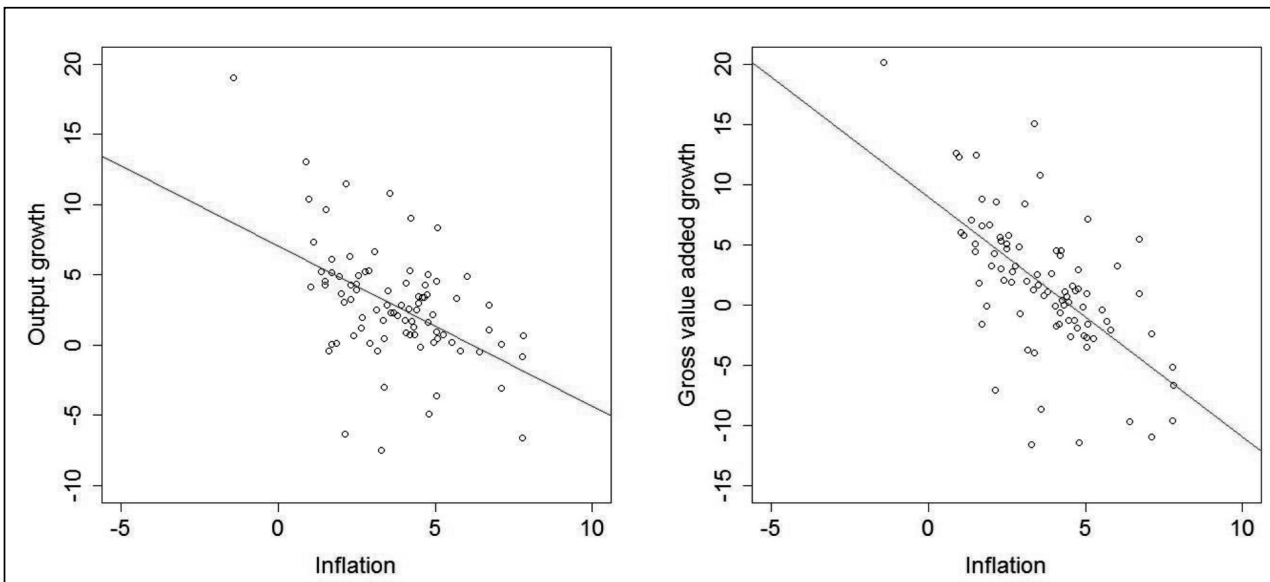

Source: Czech Statistical Office (2017), own computations 
the contracting sectors had both low and high inflation, booming sectors tended to have lower inflation and those that expanded most quickly - with growth rate of output above $10 \%$ - had exclusively low inflation or outright deflation.

The results suggest that higher output growth is linked to slower price growth, i.e. low inflation or outright deflation. However, it may not be evident what happens to firms' profits as inflation slows or turns into deflation. We therefore used growth in real gross value added instead of real output growth and regressed it on price growth. The results are very similar to those with output growth (see Tab. 3 and Fig. 3).

Overall, this evidence too seems to run against the deflation-recession theories. In our sample, faster output growth and profit growth are associated with slower inflation or outright deflation. This could suggest that higher production most often results from investment into lower-cost production, to which consumers react by purchasing more.

\subsection{Panel Data \\ Two Models}

Using panel data naturally offers much more information than time averages because we can make use of the entire variation of annual observations. Our data are in the form of balanced panel data and we use the fixed effects model for estimation. This model allows unobserved sector-specific effects to have any correlation with the explicit regressors. We estimated the models below using the so-called 'within estimation'.

Generally, we use two economic models for estimation. The first is an autoregressive distributed lag (ADL) model which takes a macroeconomic approach to prices and production. Just as studies cited in Section 1.1 regress GDP growth on price growth (inflation or deflation), we regress sector output growth on the respective growth in output prices for the given sector. This directly addresses the question of correlation between prices and output. We also include lagged variables. For example, we estimate

$$
q_{i t}=\hat{a}_{0}+\hat{a}_{1} q_{i t-1}+\hat{a}_{2} p_{i t}+\hat{a}_{3} p_{i t-1}+a_{i}+u_{i t}
$$

where $q_{i t}$ is real output growth in sector $i$ and year $t, p_{i t}$ growth in output prices in the sector (both in percent terms), $a_{i}$ the sector-specific unobserved effect and $u_{i t}$ the error term.
The second model, in contrast, takes a more microeconomic, firm-level approach. To produce output, firms must employ workers and buy intermediate inputs. Therefore, the model we estimate is

$$
q_{i t}=\hat{a}_{0}+b_{1} p_{i t}+\hat{a}_{2} e m p_{i t}+\hat{a}_{3} i n p_{i t}+a_{i}+u_{i t}(2)
$$

where emp is growth in labour employed (measured in total hours worked) and inp growth in the volume of intermediate inputs in production.

The regressors include two usual inputs in the neoclassical production function (for why we exclude capital $K$, see our discussion below) plus a special term - the output price change $p$. Productivity, or efficiency of production, is usually accounted for as a residual, i.e., what remains unexplained in output produced if we take into account changes in labour, capital and intermediate inputs. Firms typically invest or take other measures in order to make production more efficient. After they do so, they can produce more and with lower costs, so they can offer their products more cheaply and reach more customers. If this is the case, then the output price $P$ acts as a proxy for efficiency. The lower is the cost of production, the lower is the observed price $P$. Therefore, price growth $p$ is not only a variable that we add to find out about its correlation with output growth $q$, but it also has a concrete economic interpretation as a proxy for the efficiency of production.

Equation 1 above contains the lagged dependent variable $q_{i t-1}$ among regressors. As a result, the fixed-effects estimator is generally not consistent. As Wooldridge (2002) shows, the bias falls at a rate $1 / T$ as $T$ grows, and for a time dimension high enough, the inconsistency would be negligible. We think that with our $T=22$, we do have a $T$ high enough to be sure that most of the bias disappears. However, as a check we also perform General Method of Moments (GMM) estimation in equations where there are lagged dependent variables. Our GMM estimation follows Arellano and Bond's (1991) two-step procedure and we use lags of order 2 to 5 of the dependent variable as instrumental variables. Finally, in the fixed effects models below, each regression was tested for heteroscedasticity and serial correlation. When either of these was detected, a robust variance matrix estimator was used to correct the variances and test statistics. 


\section{Results: Macroeconomic Approach}

In the first, macroeconomic approach, we estimate the effect of inflation on output growth and GVA growth in an autoregressive distributed lag model. Tab. 4 shows that contemporaneous inflation $p_{t}$ is negatively linked with output growth, confirming our findings from Section 4.1 above. The GMM estimation brings an estimate of the coefficient of $p_{t}$ very similar to the fixed effects estimation ( -0.303 vs. -0.293$)$ and confirms its statistical significance. By contrast, the coefficient of $p_{t-1}$ is economically and statistically less significant, both according to fixed effects estimation and GMM. Similarly to output, inflation is negatively linked to the growth in gross value added of firms (see the lower half of Tab. 4).

The only difference is that the magnitude of the coefficient of $p_{t}$ is bigger for gross value added than for output as dependent variable. This is understandable since firms usually have operating leverage: a rise in output (revenues) by $1 \%$ causes a rise in gross profit of more than $1 \%$.

\section{Results: Production-Function Approach}

In the second, more microeconomic approach, we use typical inputs into production function as control variables for assessing the impact of inflation on output growth. These should be more powerful control variables as they are directly linked to output. We estimate the equation with growth in labour emp (total hours worked) and growth in the volume of intermediate inputs inp as controls.

We have also added growth in gross capital stock $k$ to imitate more the traditional production function $Y=f(L, K)$. Because data on capital stock have poorer availability than other data, we used an alternative source from the OECD (2016). It is both narrower (only 57 sectors) and shorter (1995-2009) than our main dataset, so it has much fewer observations (798). Results from this enlarged regression that includes $k$ are not materially different from those reported in Tab. 5 and we do not report them here.

As expected, this model shows a much higher fit as Adj. $R^{2}$ is as high as 0.638 in the output regression in Tab. 5. And again, inflation negatively affects output growth $(-0.476)$ with high statistical significance. Labour and intermediate inputs also have the expected signs and high significance. In the GVA regression, inflation also has a negative coefficient and the coefficient is again greater in absolute magnitude. Interestingly, while the labour input has a positive and statistically significant impact on GVA, intermediate inputs lose their significance.

\section{Interpretation}

The empirical results bring, in our view, two important findings.

\section{Tab. 4: ADL: Regression of growth in output and GVA on inflation}

\begin{tabular}{|c|c|c|c|c|}
\hline & \multicolumn{2}{|c|}{ Fixed effects } & \multicolumn{2}{|c|}{ GMM } \\
\hline & Coefficient & $p$-value & Coefficient & p-value \\
\hline \multicolumn{5}{|c|}{ Regressing $q_{t}$ on: } \\
\hline $\mathrm{q}_{\mathrm{t}-1}$ & 0.012 & 0.696 & 0.042 & 0.231 \\
\hline$p_{t}$ & $-0.293^{* * *}$ & 0.003 & $-0.303^{* *}$ & 0.014 \\
\hline$p_{t-1}$ & $0.136^{*}$ & 0.052 & 0.110 & 0.121 \\
\hline Observations & \multicolumn{2}{|c|}{1,806} & \multicolumn{2}{|c|}{1,720} \\
\hline Adj. $R^{2}$ & \multicolumn{2}{|c|}{0.017} & \multicolumn{2}{|c|}{ - } \\
\hline \multicolumn{5}{|c|}{ Regressing gva $_{\mathrm{t}}$ on: } \\
\hline $\mathrm{gva}_{\mathrm{t}-1}$ & $-0.086^{\star * *}$ & 0.002 & -0.178 & 0.236 \\
\hline$p_{t}$ & $-1.614^{* * *}$ & $<0.001$ & $-1.768^{* * *}$ & $<0.001$ \\
\hline $\mathrm{p}_{\mathrm{t}-1}$ & 0.614 & 0.173 & 0.393 & 0.617 \\
\hline Observations & \multicolumn{2}{|c|}{1,806} & \multicolumn{2}{|c|}{1,720} \\
\hline Adj. $R^{2}$ & \multicolumn{2}{|c|}{0.068} & \multicolumn{2}{|c|}{ - } \\
\hline
\end{tabular}

Source: Czech Statistical Office (2017), own computations

Note: The sign * denotes statistical significance at $10 \%,{ }^{* *}$ at $5 \%$ and ${ }^{* \star *}$ at $1 \%$ level. 


\section{Tab. 5: Production function: Regression of growth in output and GVA on inflation}

\begin{tabular}{|c|c|c|}
\hline & \multicolumn{2}{|c|}{ Fixed effects } \\
\hline & Coefficient & p-value \\
\hline \multicolumn{3}{|l|}{ Regressing $q_{t}$ on: } \\
\hline$p_{t}$ & $-0.476^{* * *}$ & $<0.001$ \\
\hline$e p_{t}$ & $0.280^{* * *}$ & $<0.001$ \\
\hline inp $_{t}$ & $0.582^{\star \star *}$ & $<0.001$ \\
\hline Observations & \multicolumn{2}{|c|}{1,700} \\
\hline Adj. $R^{2}$ & \multicolumn{2}{|c|}{0.638} \\
\hline \multicolumn{3}{|l|}{ Regressing gva $_{\mathrm{t}}$ on: } \\
\hline$p_{t}$ & $-1.663^{* * *}$ & $<0.001$ \\
\hline $\mathrm{emp}_{\mathrm{t}}$ & $0.889^{* * *}$ & $<0.001$ \\
\hline inp $_{t}$ & 0.062 & 0.637 \\
\hline Observations & \multicolumn{2}{|c|}{1,700} \\
\hline Adj. $R^{2}$ & \multicolumn{2}{|c|}{0.112} \\
\hline
\end{tabular}

Source: Czech Statistical Office (2017), own computations

Note: The sign ${ }^{* * *}$ denotes significance at $1 \%$ level.

Firstly, the negative relationship between growth in output and growth in prices suggests that observed deflation has been predominantly of the 'good' type. If falling prices resulted from falling nominal demand, firms would not respond by increasing production - on the contrary, they would cut it, as the 'bad deflation' hypothesis goes. Hence, we would observe a positive correlation between $p$ and $q$.

The alternative hypothesis is that as firms invest and improve efficiency, they manage to cut unit costs and prices. This allows them to sell more products, i.e., reach new marginal demand through lower prices. This 'good deflation' hypothesis is consistent with our findings - we see repeatedly a negative relationship between $p$ and $q$.

It could be argued that the negative relationship between $p$ and $q$ may in some more inflationary years reflect rather the comparison of high versus low inflation than inflation versus deflation. That may be true. The shift of the aggregate demand curve - for example, through central bank easing - may move the whole mass of observations to the right in Fig. 3, bringing many of them out of the deflationary section. Symmetrically, lack of aggregate nominal demand may push them to the left, which was the case for instance in 2009 when the economy as a whole had a $1.4 \%$ deflation (measured as output deflator). However, rather than focusing on the position of the mass of observations, we are interested in the slope of the regression line - that is, in the shape of the mass. Its negative slope suggests that the tendency to cut prices or at least have slower price increases than the average is associated with growing firms, not declining ones. Overall, we are not claiming that 'bad deflation' does not exist or that it cannot be harmful. We are only showing evidence that there is much more 'good deflation' than 'bad deflation' in our sample.

Secondly, using gross value added in addition to output, we have shown that lower prices are not only associated with greater output, but also with greater gross profit of firms. Output in itself is not the firms' goal, but profit is. If firms invest to increase production and cut prices, they also succeed in increasing profits, our results show. This finding is important because one line of reasoning (starting with Fisher, 1933) is that deflation or too low inflation ultimately erodes firms' profits and leads them to bankruptcies. Our results show otherwise, again providing support for the case that deflation in our sample stems from firms' own initiatives, not from negative shocks that would squeeze profits.

As pointed out in Section 2, the sectors used are not only those that produce consumer 
goods, but also those that produce capital goods or intermediate inputs for other firms. This has an important implication. Our results are not only evidence on consumers' reaction to lower prices by firms - they are also evidence on firms' reaction to lower prices by other firms, which is an area completely neglected by existing research. Therefore, we show that deflation or below-average inflation in output prices allows firms to sell more of their products to both consumers and other firms and to increase gross profits.

A comparison of our results with other studies is difficult because no other authors, to the best of our knowledge, have used sector data to inspect the relationship between prices and output or gross value added. We can only make comparisons in a broad sense - i.e., take our sector output and sector prices as counterparts to GDP and aggregate prices in other studies and compare the results. In this respect, our results generally confirm the results of Atkeson and Kehoe (2004), Borio and Filardo (2004) and Borio et al. (2015) who did not find evidence of a deflation-depression link in large datasets. Interestingly, all of these studies include pre-World War I data, which are rich in deflation. This is no coincidence, in our view. Some sectors in our dataset resemble the deflationary period 1866-1914 in the US and elsewhere which displayed frequent deflation with relatively high growth rates of output (Beckworth, 2007; Bagus, 2015). Their common feature is likely to be the underlying growth in productivity which links growth in output to reductions in prices. Our results differ from Guerrero and Parker (2006) who report negative effect of deflation on growth using lagged price change. However, their results have markedly smaller economic and statistical significance when they use a long, historical dataset (which includes pre-World War I data) than when they rely on post-World War II data. As they write: "Our results are much stronger for the postwar dataset than for the historical dataset, perhaps because the more developed economies were more likely to have experienced productivityled deflation prior to the Great Depression." (Guerrero \& Parker, 2006, p. 15.) We think that the effect of productivity improvements might be more pronounced in our study because we cover not only sectors producing for final consumption, but also sectors producing capital goods and intermediate inputs farther away in the production chain. Because the Czech economy has a relatively high share of manufacturing in total production, the effects of productivity improvements may demonstrate themselves relatively strongly in our results (In services, productivity improvements are often more difficult to achieve.).

There is one caveat to make. Our regression analysis assumes that all sectors have equal weights, which of course is not true in terms of their share in GDP, employment, etc. However, our goal was to assess deflation-recession theories. If a theory is correct, it should work both for big sectors and small ones. Therefore, from the point of view of theory, both big and small sectors should have the same weight because they all represent independent observations on which theory can be tested.

\section{Conclusion}

The sector approach that we have used in this study allows us to look 'under' aggregates such as GDP and overall inflation. While the Czech economy has seen positive overall inflation in most years (similarly to other economies), the sector analysis shows that the tendency to have deflation or lower-than-average inflation of product prices is linked to sectors with higher growth in production.

This has an important implication for the 'delayed-spending' theory of deflation and recession. If consumers and firms delayed spending in response to declining prices, it would not be the sectors with the highest production growth that have deflation in their product prices. As a result, our results cast doubt on the validity of this theory, at least in the setting of the Czech economy. Our finding also suggests that the strict view that deflation is always and everywhere harmful may well be incorrect.

Furthermore, we have also found a negative relationship between price growth and growth in gross value added. This suggests that when firms cut prices or raise them slower than the average, their gross profit does not shrink but, contrarily, grows quickly. This runs against another theory of deflation and recession one that asserts that falling prices erode firms' profits, ultimately pushing them into bankruptcy.

Overall, our results show that most of the deflationary pressures in the Czech economy in 1993-2015 have been of the 'good' type, which in our view reduces the need of monetary policy to counteract it. We believe that sector analysis 
is a promising way to expand our knowledge on the relationship between production and prices. A logical follow-up on our study would be a more detailed look at firms' profits and productivity in sectors with inflation versus those with deflation.

\section{References}

Arellano, M., \& Bond, S. (1991). Some tests of specification for panel data: Monte Carlo evidence and an application to employment equations. Review of Economic Studies, 58(2), 277-297. https://doi.org/10.2307/2297968.

Atkeson, A., \& Kehoe, P. J. (2004). Deflation and Depression: Is There an Empirical Link? American Economic Review, 94(2), 71-75. https://doi.org/10.1257/0002828041301588.

Bachmann, R., Berg, T. O., \& Sims, E. R. (2015). Inflation Expectations and Readiness to Spend: Cross-Sectional Evidence. American Economic Journal: Economic Policy, 7(1), 1-35. https://doi.org/10.1257/pol.20130292.

Bagus, P. (2015). In Defense of Deflation. Financial and Monetary Studies (41). Cham: Springer. https://doi.org/10.1007/978-3-319-13428-4.

Benhabib, J., \& Spiegel, M. M. (2009). Moderate Inflation and the Deflation-Depression Link. Journal of Money, Credit and Banking, 41(4), 787-798. https://doi.org/10.2139/ssrn.1004591.

Beckworth, D. (2007). The postbellum deflation and its lessons for today. The North American Journal of Economics and Finance, 18(2), 195214. https://doi.org/10.1016/j.najef.2006.12.003.

Bernanke, B. S. (2002). Deflation - Making Sure It Doesn't Happen Here. Speech before the National Economists Club, November 21. Washington, D.C.

Bordo, M., \& Filardo, A. (2005). Deflation and monetary policy in a historical perspective: remembering the past or being condemned to repeat it? Economic Policy, 20(44), 800-844. https://doi.org/10.1111/j.1468-0327.2005.00151.x.

Bordo, M. D., \& Redish, A. (2003). Is Deflation Depressing? Evidence from the Classical Gold Standard [NBER Working Paper 9520]. https://doi.org/10.3386/w9520.

Borio, C., \& Filardo, A. (2004). Looking Back at the International Deflation Record. The North American Journal of Economics and Finance, 15(3), 287-311. https://doi.org/10.1016/j.najef.2004.08.001.

Borio, C., Erdem, M., Filardo, A., \& Hofmann, B. (2015). The costs of deflations: a historical perspective. BIS Quarterly Review, 20(1), 31-54. https://doi.org/10.2139/ssrn.1004591.
Buiter, W. (2009). Negative nominal interest rates: Three ways to overcome the zero lower bound [NBER Working Paper 15118]. https:// doi.org/10.3386/w15118.

Czech Statistical Office. (2017). Database of National Accounts. Retrieved January 11, 2017, from http://apl.czso.cz/pll/rocenka/rocenkavyber.socas.

Fisher, I. (1933). The Debt-Deflation Theory of Great Depressions. Econometrica, 1(1), 337-357.

Guerrero, F., \& Parker, E. (2006). Deflation and Recession: Finding the Empirical Link. Economics Letters, 93(1), 12-17. https://doi. org/10.1016/j.econlet.2006.03.029.

Ichiue, H., \& Nishiguchi, S. (2014). Inflation Expectations and Consumer Spending at the Zero Bound: Micro Evidence. Economic Inquiry, 53(2), 1086-1107. https://doi.org/10.1111/ecin.12176.

Krugman, P. R. (1998). It's Baaack: Japan's Slump and the Return of the Liquidity Trap. Brookings Papers on Economic Activity, 29(2), 137-205. https://doi.org/10.1.1.320.9837.

OECD. (2016). STAN Database for Structural Analysis. Retrieved December 5, 2016, from https://stats.oecd.org/Index. aspx?DataSetCode=STAN08BIS.

Rogoff, K. (2014). Costs and benefits to phasing out paper currency [NBER Working Paper No. 20126]. https://doi.org/10.3386/w20126.

Svensson, L. E. O. (2003). Escaping from a Liquidity Trap and Deflation: The Foolproof Way and Others. Journal of Economic Perspectives, 17(4), 145-166. https://doi. org/10.1257/089533003772034934.

Wooldridge, J. M. (2002). Econometric Analysis of Cross Section and Panel Data. Cambridge, MA: MIT Press. https://doi. org/10.1007/s00712-003-0589-6.

Mgr. Pavel Ryska, M.Phil. Jan Evangelista Purkyně University in Ústí nad Labem Faculty of Social and Economic Studies and

Charles University Faculty of Social Sciences Institute of Economic Studies

Czech Republic pavel_ryska@volny.cz

Ing. Petr Sklenár̆ J\&T Banka, a.s. Czech Republic sklenar@jtbank.cz 


\section{Appendix}

In Section 3, we explored how much growth in production or GVA there is under inflation and deflation. To give a complete picture, we now reverse our perspective and look into how prices grow under increases versus decreases in production or GVA.

As seen in Tab. 6, the average growth of prices is significantly higher when production decreases. In addition, there are more observations of deflation when production grows $(23.1 \%)$ than when production declines (15.7\%).

By the same token, prices grow slower under increasing GVA than under decreasing GVA. Relatively more cases of deflation are recorded when GVA grows $(27.4 \%)$ than when it falls $(10.6 \%)$.

The statistical tests in Tab. 7 conclude that neither the average price changes nor variances of prices changes are equal and that this result is valid for both production and GVA. In other words, the average growth of prices is significantly higher when production or GVA falls.

Finally, we visualize our findings in Fig. 4. It is the observations with production and GVA increase that tend to have slower price growth or outright deflation.

In sum, our finding from Section 3 also works the other way round: not only is deflation associated with quicker output growth than inflation, but output increases are usually accompanied by lower growth of prices than output decreases.

\section{Tab. 6: Growth of prices under increase and decrease of production or GVA}

\begin{tabular}{l|c|c|c} 
& All data & Production increase & Production decrease \\
\hline Observations & 1,892 & 1,154 & 738 \\
\hline Price change & & & \\
\hline obs. with price increase & $79.8 \%$ & $76.9 \%$ & $84.3 \%$ \\
\hline obs. with price decrease & $20.2 \%$ & $23.1 \%$ & $15.7 \%$ \\
\hline Average price growth & 3.71 & 2.82 & 5.09 \\
\hline Price growth st. deviation & 6.14 & 4.88 & 7.51 \\
\hline & All data & GVA increase & GVA decrease \\
\hline Observations & 1,892 & 1,087 & 805 \\
\hline Price change & & & $89.4 \%$ \\
\hline obs. with price increase & $79.8 \%$ & $72.6 \%$ & $10.6 \%$ \\
\hline obs. with price decrease & $20.2 \%$ & $27.4 \%$ & 5.65 \\
\hline Average price growth & 3.71 & 2.26 & 6.65 \\
\hline Price growth st. deviation & 6.14 & 5.30 &
\end{tabular}

Source: Czech Statistical Office (2017), own computations 


\section{Ekonomie}

\section{Tab. 7: \\ Test of equality of means and variances}

\begin{tabular}{c|c|c} 
& Test statistic & p-value \\
\hline Price growth under production increase/decrease & & \\
\hline t-test for equality of means & 7.30 & $<0.001$ \\
\hline F-test for equality of variances & 2.36 & $<0.001$ \\
\hline Price growth under GVA increase/decrease & & \\
\hline t-test for equality of means & 11.9 & $<0.001$ \\
\hline F-test for equality of variances & 1.58 & $<0.001$ \\
\hline
\end{tabular}

Source: Czech Statistical Office (2017), own computations

\section{Fig. 4: Density of price growth under production growth and production decline}

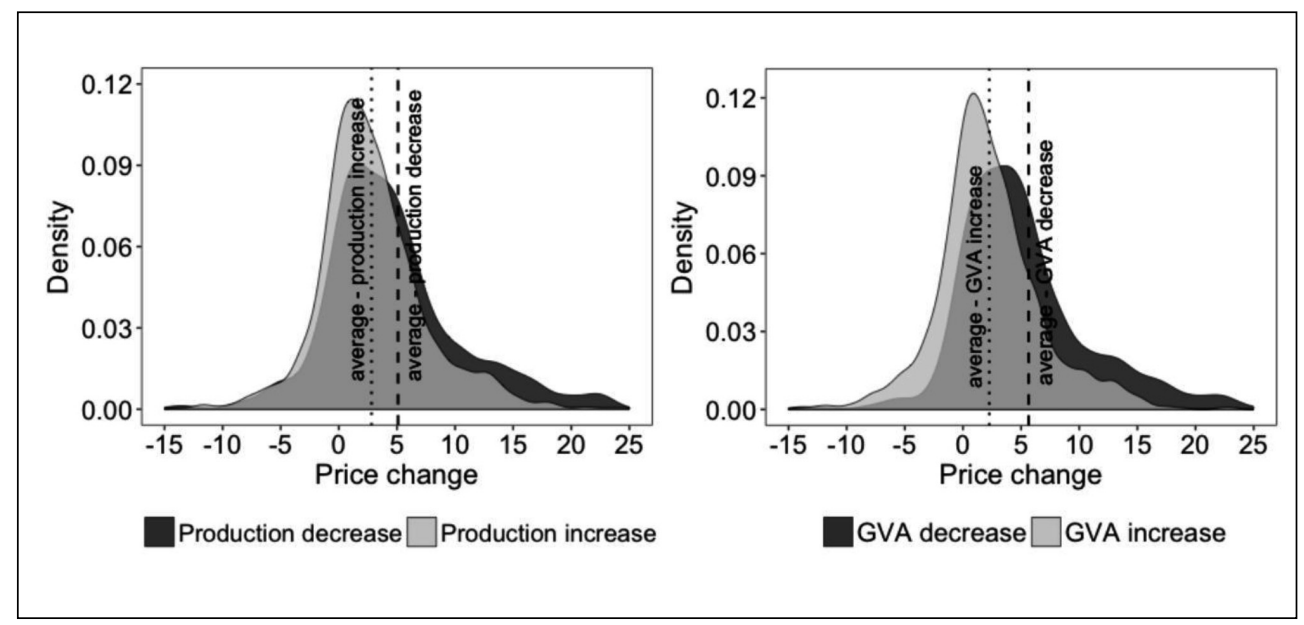

Source: Czech Statistical Office (2017), own computations 


\section{Abstract}

\section{DEFLATION AND OUTPUT ACROSS SECTORS: RESULTS FOR THE CZECH REPUBLIC}

\section{Pavel Ryska, Petr Sklenár̆}

The present paper looks into the relationship between deflation and economic output. Previous studies relied uniquely on annual macroeconomic data on GDP and prices, which caused lack of observations on deflation. This paper uses panel data on 86 sectors of the Czech economy in 1993-2015, which offer more variation in price changes and display frequent observations of deflation. Our goal is to test the hypothesis whether deflation negatively affects output growth as is commonly thought - and whether central banks should counter all deflation that appears. The most common argument against deflation is that decreasing prices lead consumers and firms to postpone purchases, which in turn depresses output.

We find that (1) sectors with output price deflation and below-average inflation have higher growth rate of output, and that (2) these sectors also tend to show quicker growth in gross value added. This evidence contradicts the often held notion that deflation is linked with recession or subpar growth. It also shows that firms with deflating output prices do not have trouble preserving their profits. Deflation observed in the Czech economy in 1993-2015 is likely to be the result of falling unit costs enabled by firms' investment rather than the result of falling demand. This might have policy implications. Our results highlight that monetary policy should differentiate among sources of deflation and that deflation observed in the Czech Republic has been rather of the 'good' type. We believe that our approach using sector data is novel because it uncovers more variation in prices and output than the more common approach that uses macroeconomic aggregates.

Key Words: Deflation, price level, economic growth, panel data.

JEL Classification: E31, C33, N10.

DOI: 10.15240/tul/001/2018-4-007 